\title{
Structure and Performance of the Retail Outlets of Honey in the Kingdom of Saudi Arabia
}

\author{
Ahmed A. Al-Ghamdi' ${ }^{1}$ Abdu Zulail'2, Nuru Adgaba' ${ }^{1}$ \\ ${ }^{1}$ Department of Plant Protection, College of Food and Agriculture Sciences, King Saud University, \\ Riyadh, KSA \\ ${ }^{2}$ Department of Agricultural Economics, College of Food and Agriculture Science, King Saud University, Riyadh, \\ KSA \\ Email: amzolil@gmail.com
}

Received 27 April 2014; revised 8 June 2014; accepted 18 June 2014

Copyright (C) 2014 by authors and Scientific Research Publishing Inc.

This work is licensed under the Creative Commons Attribution International License (CC BY).

http://creativecommons.org/licenses/by/4.0/

(c) (i) Open Access

\section{Abstract}

The study aimed at analyzing the most important factors affecting the retail marketing of honey in Saudi Arabia. Cross sectional survey was employed using field interview (direct contact) with a random sample of 343 retail outlets represented all its forms and patterns in seven major cities in Saudi Arabia. Measurements like market share, Gini coefficient and Herfindahl Hirschman Index (HHI) were used to estimate the indicators of market structure and its performance. The result showed that the structure of honey retail market is generally closer to pure competition with a small concentration in some areas. Gini coefficients of concentration, as well as the values of the Herfindahl Hirschman Index (HHI) were relatively low for retailers. The average marketing margin was about SAR $6.4 / \mathrm{Kg}$ for local honey while the marketing margin of imported honey was about SAR 113/Kg. The high profit margin variation between local and imported honey is due to the high marketing costs, lower supplied quantity and higher demand for local honey. The estimated cost of marketing of onekilogram of honey was about 8 SAR at the retail level. From retailers' point of view, low quality, lack of marketing services, improper display, high rental property, lack of knowledge and experience of the consumer about properties and quality characteristics honey, high prices and shortage of some varieties of honey in some specific season are the most important problems of honey marketing in the Saudi market. Setting priorities between different brands of honey plays a noticeable role in marketing. Some honey producers and traders were very concerned about unfair competition of honey market through high promotion as a brand based on their long history in the production and supply of high-quality varieties of honey from specific and well-known varieties. Hence, intensive awareness creation effort through training, exhibition, media and advertisement are required to improve the perception of consumers towards the local honey. 


\section{Keywords}

\section{Honey, Marketing, Performance, Retail Outlets, Structure, Saudi Arabia}

\section{Introduction}

The economic theory explained the importance of services and marketing functions in the formation of composite demand of consumer [1]. It is obvious that the trend of honey demand and its marketing services is increasing dramatically at the level of retail markets in Saudi Arabia. The outlets of honey sales became numerous and varied significantly at the retail level, and has become a strategic link in the marketing of honey. It represents the mirror that reflects the reality of the interactions between the market of honey and its marketing services.

The study and analysis of the structure and performance of honey retail outlets is very important due to its impact on the efficiency of marketing system of honey in its entirety, especially in the presence of increasing complains of producers from the relative low prices they receive, the small export amount of Saudi Arabia honey and increasing of local consumption.

[2] explained the four known structures of markets which are pure competition, monopolistic competition, oligopoly and pure monopoly. He explained that the mutual interdependence between the corporations is a characteristic exclusive to oligopoly. He also linked between structure, behavior and market performance. [3] reported that the structure of market is affected by many factors related to supply and demand. Furthermore, the nature of facilities within the market is associated with its competitive strategies and influenced to a large extent by the regulatory aspects. They also suggested that the good market performance should achieve optimal use of the factors of production, reasonable profitability and price stability and ensures a good level of growth. The good performance of market is associated with structure and behavior. The study of [3] also showed that the most important criteria for determining the structure of market is the concentration ratio and that market power that enables some facilities to earn increased profits.

[4] studied the relationship between the structure of the market and its performance achieved by the level of profitability in manufacturing industries and applied on some producing factories in the Philippines.

[5] discussed the impact of market structure on the marketing margin using the concentration ratio of four biggest facilities to reflect the level of market structure. Moreover, [2] showed some of the criteria that can be used to measure the concentration of the market such as the market share of the biggest four, eight or twenty facilities in the market, using Herfindhal Hirschman Index (HHI) and Gini Coefficient. Moreover, [6] showed that the most important factors that influenced the vegetables and fruits market situations are the changes in the composition of final demand, the trend toward more marketing services, as well as changes in expected supply because of the quality of the product, transportation and storage.

[7] has studied the market structures in Saudi Arabia and he suggested some reforms like clustering of farmers in agricultural marketing cooperatives, developing of appropriate solutions to regulate the market in all aspects, raising of the initial selling prices for local agricultural products to promote and to ensure the continuation of farmers in agricultural activity.

Honey represents a sizeable niche in the economic structure of Saudi Arabia agricultural economy and sizeable segment of farmers (honey producers and beekeepers) economy in Saudi Arabia, not only at the production level, but also on the level of consumption and marketing. The government is highly interested and taking responsibility to support the beekeeping industry through providing beekeepers subsidy and loan grants.

The activity of honey market in Saudi Arabia, like the other economic activities is subjected to the principle of supply and demand and the availability of goods and services with desired characteristics that satisfy the needs of the consumer. Honey market is attaining a remarkable development due to the strong cultural, social and religious association of the people with honey, in Saudi Arabia.

Producing of honey is one of agricultural activities which have shown a noticeable development in Saudi Arabia. Currently the annual honey production of the country estimated to be 9000 tons [8].

Saudi Arabia imports honey from a range of countries like Mexico, Pakistan, Germany, Yemen and Argentina. Saudi Arabia imports significant volume of bulk honey that ranges from 2019.1 tons in 1994 to an upper limit of 13541.7 tons at an average of $8220 \pm 3881.23$ tons with the coefficient of variation of $47.3 \%$ during the studied 
period.

Furthermore, Saudi imports of bulk honey have increased with an annual growth rate of $10.1 \%$ during the studied period. The value of imports of bulk honey have ranged from a lower limit of US\$ 8034494.4 in 1994 and an upper limit reached US\$29,480,000 in 2009 [9].

Despite shortage of natural honey in Saudi Arabia, a part of the imported amount is re-exported to other countries, mainly Algeria, Jordan and the Gulf Cooperation Council (GCC). The volume of Saudi exports of honey reached 1244 tons with a value of US\$ 5,486,000 [9]. So the net consumption amount of honey is about 17,843 tons.

Despite honey markets have attracted the attention of many researchers in general, such as [10]-[12], however, none of the study has attempted to analyze the structure and performance of the retail markets for honey. With this general background, the aim of this study was to analyze the most important aspects of the structure and performance of honey market at the retail level following the procedures of [13] [14] which link between profitability and marketing efficiency and market structure. The study focuses on assessing the current situation of honey market of the study area; analyzing the structure of honey retail market and analyzing the marketing margin and market performance at the retail level.

\section{Research Methodology}

The study was mainly based on primary field data collected from a randomly sampled 343 retail outlets that respondent in all its forms and patterns in seven major cities of Saudi Arabia (Riyadh, Jeddah, Ta'if, Dammam, Tabuk, Asir and Jizan). Data were collected through direct contact (face to face) and interviewing of retailers in their outlets. The major variables included in the interview were: nationality, educational level, retailers' basic job, the proportion of the annual income of retailers from honey trade, annual trading volume of honey, honey quality characters, outlets to get the honey, the motives of honey consumption, the problems of honey marketing and the comparison of honey prices with most important characteristics.

The types of honey have also been considered as a variable that represented in the sample that has an impact on the price of honey from retailers' point of view in Saudi Arabia. In addition secondary data derived from some official sources were included.

Some measurements like market share, Gini coefficient and Herfindahl Hirschman Index (HHI) and standards were used to measure market structure and performance indicators. Descriptive statistical, analysis of Variance were utilized to analyze data using SPSS version 15.

\section{Standards of Market Structure and Performances}

To measure the market structure and performances the following equations were adopted:

\subsection{Market Share}

Market share for the biggest four, eight and twenty outlets that represents a ratio of outlets' sales to the total sales of all the outlets were determined following [15] equation:

$$
M C=\frac{\sum_{1}^{n} C_{i}}{\sum_{1}^{N} C_{i}} \times 100
$$

where, $M C$ is market share of the four or eight outlets, " $C$ " is the market share of outlet "I", " $n$ " is 4 or 8 and " $N$ " is total number of outlets.

\subsection{Gini Coefficient}

Gini coefficient is one of the important and common measurements that used in measuring the fairness of market distribution. It depends on the idea of Lorenz curve. Moreover, it gives a digital measurement for market concentration ratio. Gini coefficient value is between zero and one. The lower the Gini coefficient value, the higher the distribution fairness.

Gini coefficient was calculated following Sawyer, [16] equation. 


$$
\text { [14] } G=\frac{\sum Y_{t} X_{t+1}-\sum X_{t} Y_{t+1}}{10000}
$$

where, "G" is Gini coefficient, " $Y$ " is ascending cumulative frequency of the percentages of number of retails' outlets, " $X$ " is ascending cumulative frequency of the percentages of the market shares, " $t$ " is record order and " $t$ +1 " is next record.

\subsection{Herfindahl Hirschman Index (HHI)}

This measurement gives higher relative weighs for the share of bigger facilities. It usually used to determine whether the merging of facilities lead to monopoly power or not. This measurement is more pronounced in case of the competition between the large number of outlets. In the case of full market monopoly where one facility has full market share, the HHI value is equal to 10,000 [17].

HHI was calculated according to the following equation [17].

$$
\text { [17] } H H_{i}=\sum_{i=1}^{n} c s^{2}
$$

where, " $H H_{i}$ " is Herfindahl Hirschman Index, " $S$ " is size of applied activity " $C$ " compared with all outlets activities, "i" is specific outlet, and " $n$ " is total number of outlets.

\section{Results and Discussion}

Out of the 343 retails' outlets 49, 75, 50, 38, 33, 60 and 37 were distributed over seven cities of Saudi Arabia: Riyadh, Jeddah, Ta'if, Dammam, Tabuk, Asir and Jizan, respectively. The results showed that about $78 \%$ of retailers have Saudi nationality, while about 22\% from other nationalities Table 1 . Furthermore, $0.3 \%$ of retailers do not have any educational qualifications, $2.8 \%$ of them have elementary certificates, $10 \%$ have preparatory certificates, $20 \%$ have secondary school certificates, $40 \%$ have first degree university certificates and $23.5 \%$ have higher education(post graduate) certificates (Data collected from retails outlets, 2012). Generally the data indicated that significant proportion of the retailers were educated.

The contribution of honey trade to the total annual income of honey retailers varied from $5 \%$ and $100 \%$ with a mean of $65 \%$ Table 2, which indicates that trading of honey play a great role as means of income source for large number of people in the country.

Table 1. The share of honey trade in annual incomes of retailer.

\begin{tabular}{c|ccccc}
\hline & $\mathrm{N}$ & Minimum & Maximum & Mean & Std. Deviation \\
\hline Importance of honey trade out of annual income & 327 & $\% 5$ & $\% 100.00$ & $\% 64.6789$ & 30.46628 \\
\hline
\end{tabular}

\begin{tabular}{|c|c|c|c|}
\hline & & Frequency & $\%$ \\
\hline \multirow{2}{*}{ Nationality } & Saudi & 267 & 78 \\
\hline & Others & 74 & 22 \\
\hline \multirow{6}{*}{ Educational Level } & Neither Read Nor write & 1 & 00.3 \\
\hline & Elementary & 9 & 02.8 \\
\hline & Preparatory & 32 & 10.0 \\
\hline & Secondary & 64 & 20.1 \\
\hline & University & 121 & 37.9 \\
\hline & Higher Education & 75 & 23.5 \\
\hline \multirow{4}{*}{ Basic Job } & Government Job & 41 & 12.7 \\
\hline & Private Sector Job & 1 & 00.3 \\
\hline & Business & 140 & 43.2 \\
\hline & Honey Dealer & 142 & 43.8 \\
\hline
\end{tabular}

Table 2. Socio-economic profiles of sampled honey retailers in Saudi Arabia. 


\subsection{Structure of Honey Retail Market in Saudi Arabia}

Analyzing the calculated values for the most important standards of concentration ratio that indicates the nature of the market structure is shown in Table 3. It was observed that the coefficient of sales concentration ratio for the largest four, eight and twenty retail outlets were $9.6 \%, 15.8 \%$ and $28.8 \%$, respectively.

From these results, it is noticeable that concentration ratio of largest four retail outlets was only $9.6 \%$ and thus, this concentration is considered desirable because the undesired ratio is $50 \%$. As well as for the largest eight facilities, it controls only $15.8 \%$ thus, this concentration is also considered desirable because the undesired ratio is expected to be $70 \%$. From these it can be said that, Saudi Arabia honey market does not suffer from undesired concentration ratio of sales with a small amount of concentration indicating that this market is moving towards full competition with a small amount of monopoly.

Furthermore, Gini coefficient for all studied retail outlets has reached 0.30 (Figure 1). This value is considered as low value indicating low sales concentration ratio in the honey retail in Saudi Arabia.

The lower value of Herfindahl Hirschman Index (HHI) indicates a lower sales concentration ratio and vice versa. In this study, HHI for all studied retail outlets had reached 77 which is a small value for HHI measurement because the value of HHI is equal to 10000 in case of full monopoly (Kock, 1980 [17]. The study clearly indicated that low sales concentration ratio hence very low level of monopoly in honey retail trade in Saudi Arabia.

$X=$ Cumulative $\%$ of retailers.

$Y=$ Cumulative $\%$ of quantity.

Gini Coefficient $=(38694.91-35694.76) / 10,000=0.300015=0.30$.

This value of Gini Coefficient (0.30) is a small value Figure 1. Hence, this also gives a clear indication of low sales concentration ratio in honey retail trade.

As a conclusion, it is obvious that the structure of honey retail market, in general, is closer to pure competition

Table 3. Measurements of structure and performance of honey retail market in Saudi Arabia.

\begin{tabular}{lcc}
\hline & Criteria & All studied retails outlets \\
\hline & For largest 4 retailers \% & $9.6 \%$ \\
Sales concentration ratio & For largest 8 retailers \% & $15.8 \%$ \\
& For largest 20 retailers $\%$ & $28.8 \%$ \\
& Gini coefficient & 0.30 \\
\hline
\end{tabular}

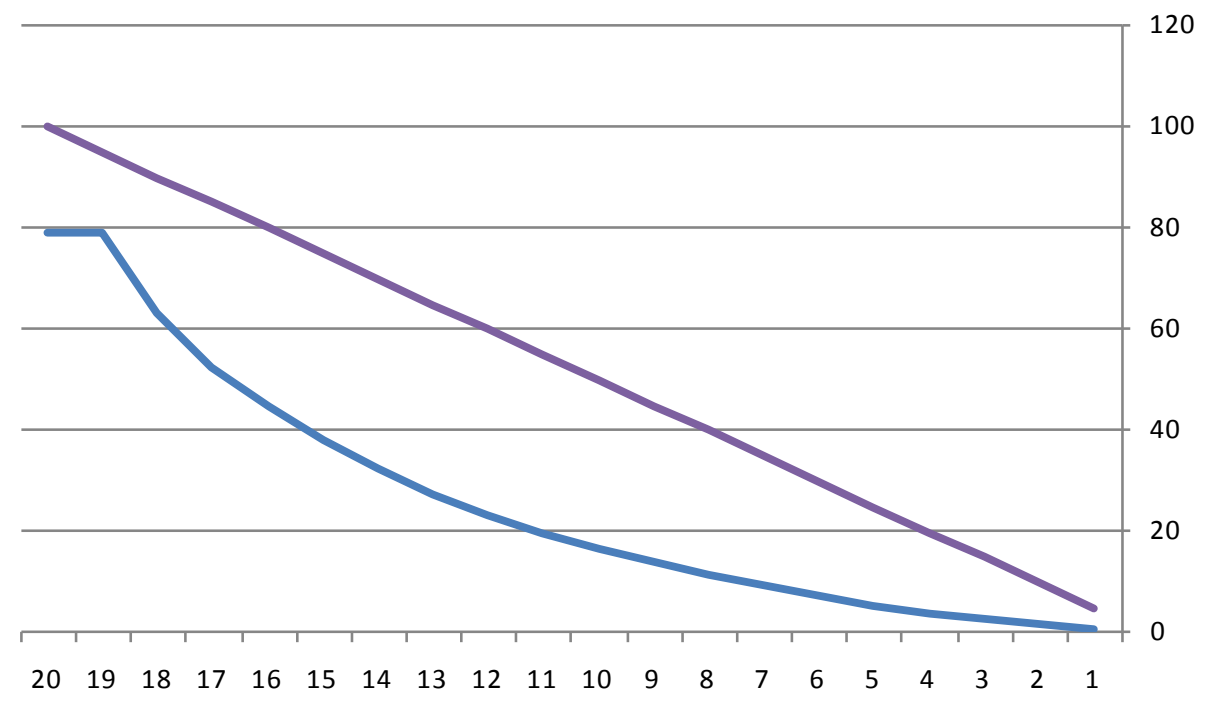

Figure 1. Lorenz curve for honey sales concentration ratio in Saudi Arabia. 
with a small portion of similarity of some aspects of monopoly. Indicators of sales concentration ratio could be considered as the most trusted in terms of the expression for honey retail structure due to presence of some disabled capitalism or human potentials are not fully exploited in some retails outlets.

\subsection{Marketing Margin}

The analysis of results of this study indicated that the average wholesale price for imported honey was SAR $62 / \mathrm{Kg}$ while the average wholesale price of local honey, in general, was about SAR 301.8/Kg.

It was also noticed that the average retail price of imported honey reached SAR $175 / \mathrm{Kg}$ whereas the average retail price of local honey was about SAR 308.2/Kg.

The average marketing margin between the wholesale and retail price of the imported honey was generally about SAR 113/Kg which is high margin, whereas the marketing margin between the wholesale and retail price of local honey, in general, was about SAR $6.4 / \mathrm{Kg}$ which is very low margin compared with the margin of imported honey prices. This may be due to the high marketing costs for local honey as well as lower supplied quantity and higher demand for local honey forcing wholesalers to seek minimum marketing margin between their price and the retailers' prices or shifting to sell their product themselves directly to the consumer instead of retailer.

The average retail price for some specific local honey such as Sidr, Sumra and Taleh were SAR 308.2, 207 and 210, respectively, while the average retail price of imported honey was SAR 175 (Table 4).

\subsection{Marketing Costs at Retail Level}

The average cost of marketing of one kilogram of honey at retail level and the most important types of expenditures according to different retail outlets are shown in Table 5. Accordingly the major expenditures are: packaging, processing and purification. In general, it has been estimated that the average marketing cost of one kilogram of honey reached about SAR 8, while the average cost of packaging reached about SAR $1.7 / \mathrm{Kg}$ and the average cost of processing reached about SAR $1.8 / \mathrm{Kg}$. In addition, the average cost of purification reached about SAR 3.7/Kg and the cost fluctuates according to the purity of honey, as well as its price. The average cost of additives reached about SAR 0.98 for imported varieties especially the Kashmiri.

\subsection{Types of Honey Prevailing in the Saudi Market and Its Quality Attributes}

Saudi market has many types of locally produced as well as imported honeys. The honey is mainly categorized according to their botanical origin used by bee to collect the nectar. Accordingly, famous honey types produced in Saudi Arabia are:

Table 4. Average retail prices of some specific honey products.

\begin{tabular}{ccccc}
\hline Package & Minimum & Maximum & Mean & Std. deviation \\
\hline 1 Kg of local honey (Sidr) & 125 & 660 & 308.1728 & 67.59795 \\
1 Kg of local honey (Sumra) & 70 & 500 & 207.3305 & 72.30603 \\
1 Kg of local honey (Taleh) & 50 & 500 & 210.9864 & 81.03878 \\
1 Kg of imported honey & 35 & 500 & 175.0000 & 139.86510 \\
\hline
\end{tabular}

Table 5. The most important items for marketing costs for one kilogram of honey.

\begin{tabular}{cccc}
\hline Cost item & Minimum & Maximum & Mean \\
\hline Packaging & 1.00 & 3 & 1.6981 \\
Processing & 0.50 & 6 & 1.7736 \\
Filtration or purification & 0.75 & 12 & 3.7170 \\
Others & 0.50 & 1 & 0.9792 \\
\hline
\end{tabular}


1) Sidwr (Ziziphus spin-christii) honey, which is differentiated based on its distinctive scent, light golden color, especially when it is fresh Sidr honey within a year after production.

2) Sumra (Acacia tortilis) honey, which is characterized by its distinct taste, dark color, which be darker as stored for longer time after production.

3) Talah (Acacia origina) honey, which is also have brown to dark color, especially if stored for long after production.

4) Majary (Hypoestesforskalii) Honey which is extremely white and with fast granulation tendency,distinctive smell, and good taste. The honey is the most expensive types of honey in the market.

5) Other honey.

There are many other imported types of honey prevailing in the Saudi market, of various species, the most important of them are:

1) Yemeni Sidr honey, several types all of them are characterized by high qualities (Hadrami Sidr, UsaimiSidr, Wosabi Sidr, etc. All of these Yemeni Sidr are having the same characteristics of locally produced Saudi Sidre, even having more quality attributes and so more price.

2) Thorn Yemeni Honey close to Sidr honey in terms of color, taste.

3) Yemeni Samar honey.

4) Pakistan Cashmiri honey, Imported Sidr honey from, Pakistan.

5) White Honey, imported from Russia and Ethiopia, it is similar to the Hungarian (Magary) local honey in terms.

\subsection{Problems of Honey Marketing in Saudi Arabia from Retailers' Point of View}

According to this survey result from retailers' point of view, low quality, lack of marketing services, inappropriate display like selling on the car, on street and so on and other problems such as high rental property, lack of knowledge or experience of the consumer about honey quality, high prices and shortage of some varieties of honey are the most important variables that create the problems of honey marketing in the Saudi market. The relative importance degrees of the various honey marketing problems are shown in Table 6, Table 7 and Figure 2.

Table 6. Relative importance of honey marketing problems from retailers' point of view in Saudi Arabia.

\begin{tabular}{ccccc}
\hline Problem & Mean & Maximum & Minimum & Std. deviation \\
\hline High price & 4.18 & 5 & 1 & 1.103706 \\
Lack of market knowledge & 3.36 & 5 & 1 & 1.136531 \\
Price Variations & 3.76 & 5 & 1 & 1.038575 \\
Low quality & 4.87 & 5 & 1 & 0.509679 \\
Shortage of local production & 3.94 & 5 & 1 & 1.107681 \\
Shortage of some varieties & 4.15 & 5 & 1 & 1.361487 \\
Lack of Mark. Services & 4.61 & 5 & 2 & 0.720566 \\
Irrelevant display & 4.45 & 5 & 1 & 0.877638 \\
Others & 4.82 & 5 & 3 & 0.474036 \\
\hline
\end{tabular}

Table 7. Importance frequency of honey marketing problems from retailers' point of view in Saudi Arabia.

\begin{tabular}{cccccc}
\hline Problem & Not important & Somewhat important & Important & Very important & Extremely important \\
\hline High price & $8(2.3)$ & $28(8.2)$ & $50(14.6)$ & $63(18.4)$ & $193(56.4)$ \\
Lack of market knowledge & $26(7.6)$ & $57(16.7)$ & $69(20.2)$ & $144(42.2)$ & $45(13.2)$ \\
Price variations & $7(2)$ & $37(10.8)$ & $80(23.4)$ & $125(36.5)$ & $92(26.9)$ \\
Low quality & $2(0.6)$ & $2(0.6)$ & $6(1.8)$ & $19(5.6)$ & $311(91.2)$ \\
Shortage of local production & $11(3.2)$ & $30(8.8)$ & $62(18.2)$ & $101(29.7)$ & $136(40)$ \\
Shortage of some varieties & $36(10.5)$ & $19(5.6)$ & $21(6.1))$ & $47(13.7)$ & $219(46)$ \\
Lack of market services & $0(0)$ & $10(2.9)$ & $18(5.3)$ & $66(19.3)$ & $148(72.5)$ \\
Irrelevant display & $3(0.9)$ & $13(3.8)$ & $32(9.4)$ & $73(21.3)$ & $221(64.6)$ \\
Others & $0(0)$ & $0(0)$ & $5(4.1)$ & $11(8.9)$ & $107(87)$ \\
\hline
\end{tabular}

The values between brackets are percentages. 


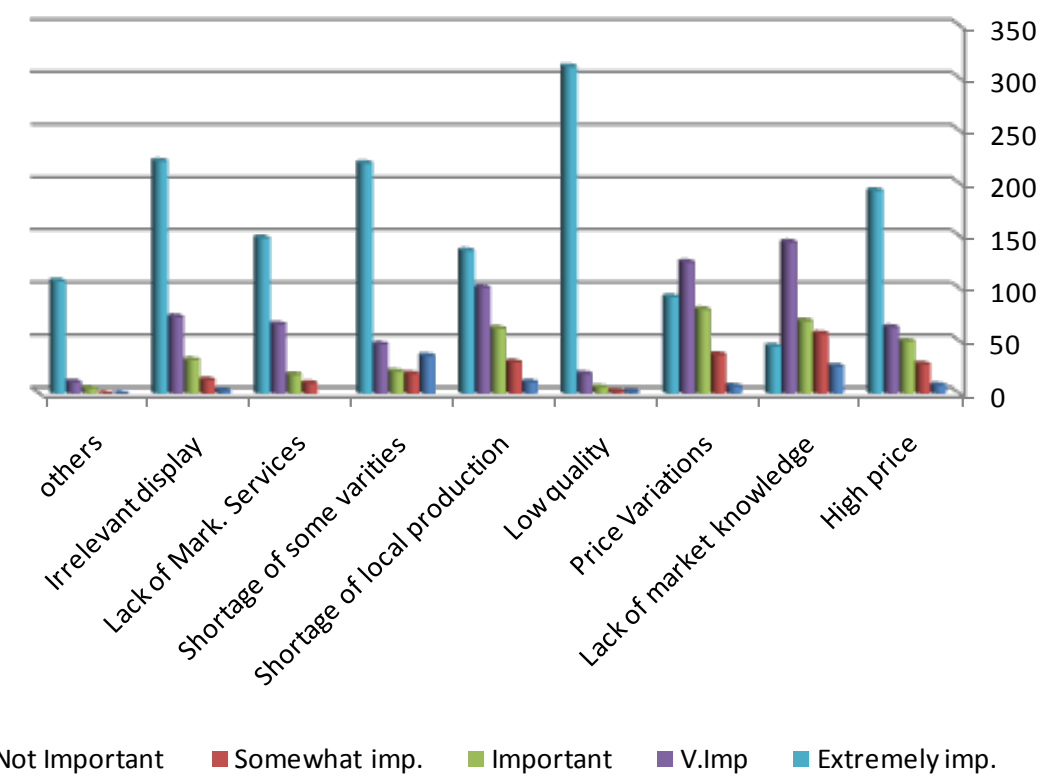

Figure 2. The importance of the problems of marketing of honey in the Saudi market.

Accordingly, 91\% of traders are considered low-quality as extremely important problem and that this problem recorded maximum relative importance degree of 4.87 out of 5 . Then, $72 \%$ of traders are considered lack of marketing services as extremely important problem in that this problem recorded high relative importance degree of 4.6 out of 5 . After that, $64 \%$ of traders are considered inappropriate displays for honey selling extremely important problem and that this problem recorded a relative importance degree of 4.5 out of 5 . Then, $64 \%$ of traders are considered shortage of some honey varieties in some specific times as extremely important problem and that this problem recorded a relative importance degree of 4.6 out of 5 . After that, $56 \%$ of traders are considered high price as extremely important problem and that this problem recorded a relative importance degree of 4.1 out of 5 . Finally, $87 \%$ of traders are considered the other problems which had not mentioned such as high rent of outlets and lack of knowledge or experience of the consumer about honey quality as extremely important problems.

Setting priorities between different brands of honey plays a noticeable role in marketing. It was obvious that some honey producers and some traders were very concerned because of the promotion of honey by brand based on their long history in the production and supply of high-quality varieties of honey from specific and wellknown varieties.

Due to free market economy, presence of competition among retailers and presence of many types of honey in the market with different quality characters, which made retailers become worried on their long history in the production and supply of high-quality varieties of honey from specific and well-known varieties.

\section{Conclusions}

Based on the results of this study, the following recommendations could be suggested:

- Providing loans and marketing subsidies for preparing qualified honey retail outlets and equipped with suitable display and storage places and facilities to maintain the quality and nature of honey.

- Increase local honey production to replace the imported sugar-based food products.

- Creating awareness through advertising campaigns and consumer education about the nutritional and pharmaceutical value of honey.

- Educating the consumer about the quality characteristics of honey in order to create consumer confidence in the product, especially local one.

- Organizing training on marketing courses for the whole sellers and retailers.

- Encouraging Saudi companies to participate meaningfully in international trade exhibitions.

- Supporting and encouraging the associations and cooperative organizations that are involved and interested in honey producing and marketing. 


\section{Acknowledgements}

The KACST and the National Plan for Science and Technology (NPST) of King Saud University (project number 11-AGR1749-02) provided the financial and technical support for this study.

\section{References}

[1] Ismail, S.M. and Mohammed, A.-H.A. (1995) Agricultural Marketing. Dar Al-Merrikh, Riyadh.

[2] Farris, P.L. (1997) Market Structure and Institution. Argo-Food Marketing International, Purdue.

[3] Viaene, J. and Gellynck, X. (1995) Structure, Conduct and Performance of the European Food Sector. European Review of Agricultural Economics, 22, 282-295. http://dx.doi.org/10.1093/erae/22.3.282

[4] Kamerschen, G., Go, L., David, R. and Charles, D.D. (1999) Market Structure and Price-Cost Margins in Philippine Manufacturing Industries. Applied Economics, 31, 827-864.

[5] Bresters, G.W. and Musick, D.C. (1995) The Effect of Market Concentration on Lamo Marketing Margins. Journal of Agricultural Applied Economics, 27, 127-183.

[6] Loseby, M. (1997) Vertical Coordination in the Fruit and Vegetable Sector: Implications for Existing Market Institution for Economic Cooperation and Development. Directorate for Food and Fisheries, OECD, Paris.

[7] Issa, S.A. (2003) The role of Efficient Agricultural Marketing in Facing Globalization Disadvantages. The Sixth Scientific Meeting for Saudi Association Arabia of Agricultural Sciences, College of Food Sciences and Agriculture, King Saud University, Riyadh.

[8] Al-Ghamdi, A.A. (2007) Beekeeping and Honey Production in Saudi Arabia. 5th Annual Conference on the Arab Beekeepers Association, Tripoli.

[9] FAO (2009) Web Page of the Food and Agriculture Organization, FAO Statistical Databases Agriculture Production, Livestock Primary.

[10] Al-Haddad, A. (2012) An Economic Analysis of Honey Production Performance in Baha Region in the Kingdom of Saudi Arabia. MSc in King Saud University, Riyadh.

[11] Shenouda, R. (2004) Saudi Arabia's Taste for Honey.

[12] Makki, M.S., Saleh, A., Issa, A.-A. and Rafi, A.-A. (1993) An Analytical Study of the Internal Marketing of Dates and Its Products in Saudi Arabia and the Popular Marketing Patterns in Its and Suggestions to Improve the Efficiency of Its Marketing. Publications of The Third Symposium of Date Palm, King Faisal University, Al-Ahsa.

[13] Caves, R. (1987) American Industry: Structure, Conduct, Performance, 6th Edition, Prentice Hall, Upper Saddle River, 98.

[14] Hazledine, T. (1989) Market Power or Relativity Efficiency? An Examination of Profitability Performance in the Canadian Food and Beverage Sector. Agribusiness, 5, 25-42. http://dx.doi.org/10.1002/1520-6297(198901)5:1<25::AID-AGR2720050104>3.0.CO;2-W

[15] Ramez, W.S.M. (1997) Strategic Marketing. Dar Al-Kotob Al-Qataria, Doha.

[16] Sawyer, M.C. (1981) The Economic of Industrial firms: Theory, Evidence and Policy. London.

[17] Kock, J. (1980) Industrial Organnization Prices. 2rd Edition, Prentice Hall Inc., Upper Saddle River. 
Scientific Research Publishing (SCIRP) is one of the largest Open Access journal publishers. It is currently publishing more than 200 open access, online, peer-reviewed journals covering a wide range of academic disciplines. SCIRP serves the worldwide academic communities and contributes to the progress and application of science with its publication.

Other selected journals from SCIRP are listed as below. Submit your manuscript to us via either submit@scirp.org or Online Submission Portal.
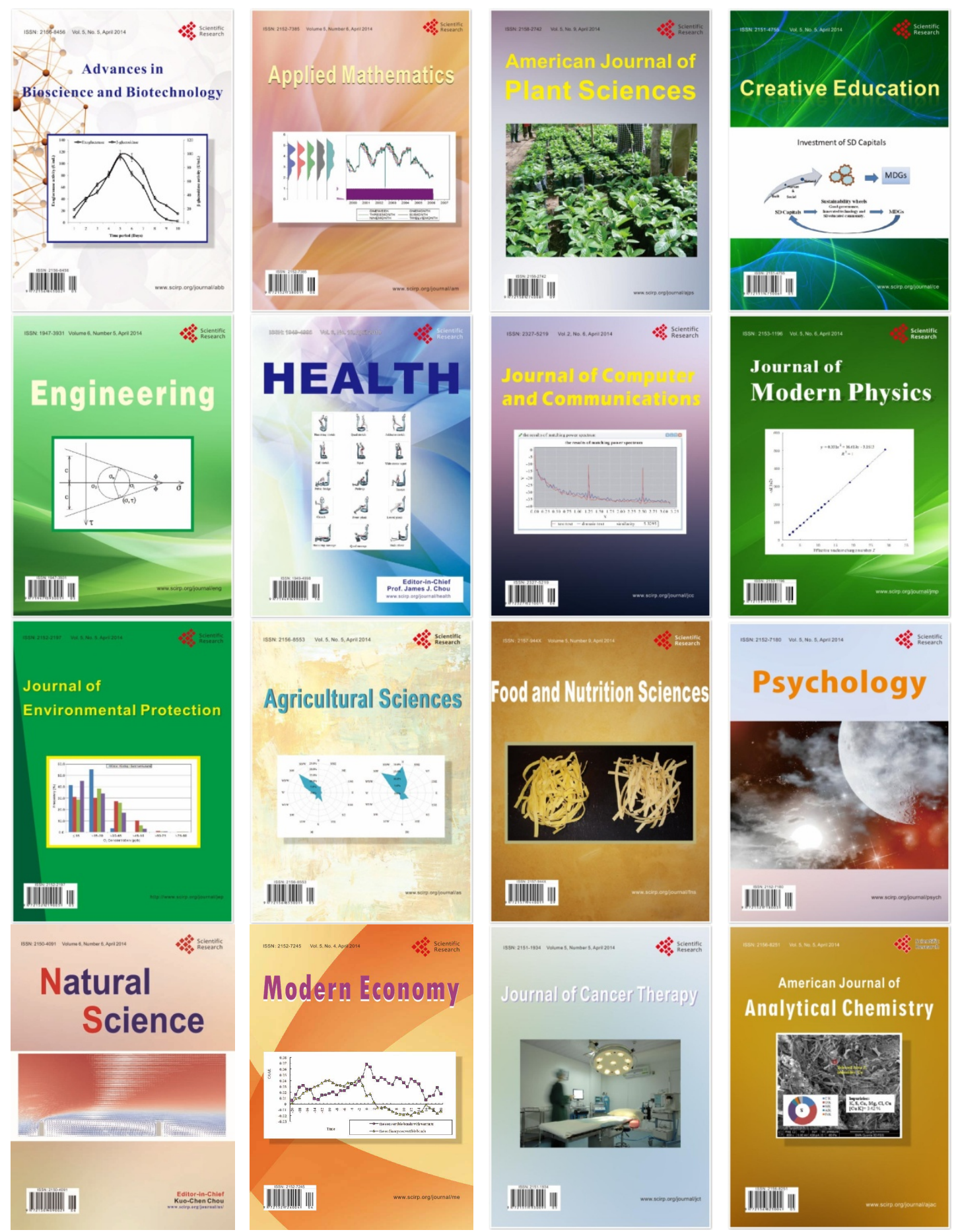